
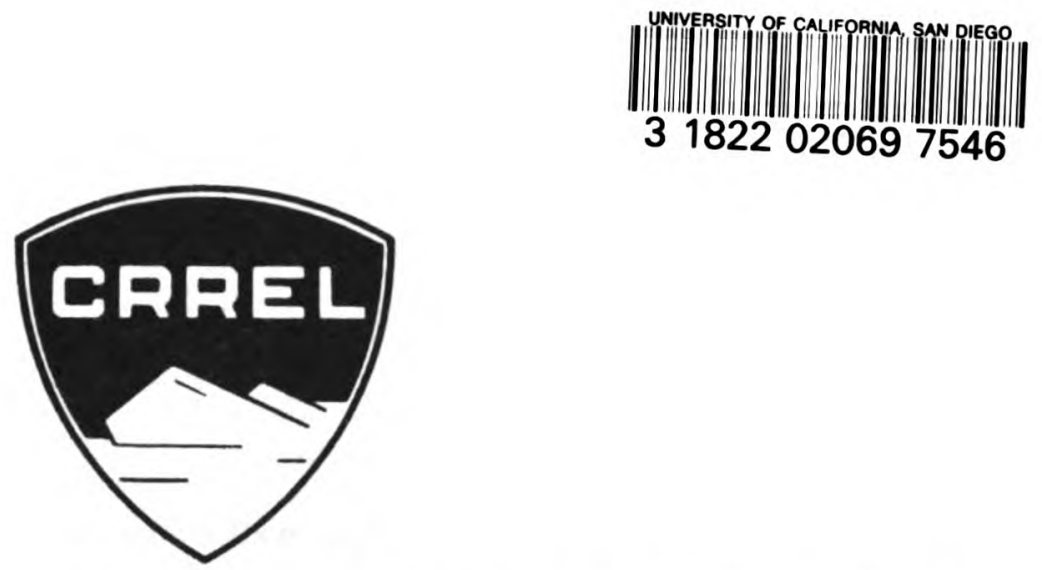

COLD REGIONS SCIENCE AND ENGINEERING

Part II: Physical Science

Section C: Physics and Mechanics of Ice

\title{
THE \\ MECHANICAL PROPERTIES OF SEA ICE \\ by
}

W. Weeks and A. Assur

SEPTEMBER 1967

U.S. ARMY MATERIEL COMMAND

COLD REGIONS RESEARCH \& ENGINEERING LABORATORY

HANOVER, NEW HAMPSHIRE

DA Project IVO25001A130

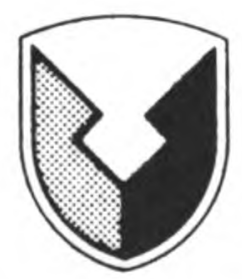

Dicribition of this document is unlimited 